\title{
Pneumonia due to aspiration of povidine iodine after induction of general anesthesia -A case report-
}

\author{
Tae Hun An, and Byung Ryang Ahn \\ Department of Anesthesiology and Pain Medicine, School of Medicine, Chosun University, Gwangju, Korea
}

Aspiration pneumonia is usually caused by aspiration of gastric contents during anesthesia. It causes severe pulmonary complications. Povidone iodine was used widely as an oral antiseptic. Although povidone iodine is thought to be a safe and effective antiseptic, severe complications from its aspiration may occur. We present a case of pneumonia secondary to aspiration of povidone iodine in a 16 year old female patient who underwent orofacial surgery. Aspiration pneumonia must be treated immediately. Mechanical ventilation with PEEP and periodical bronchial toilet with fiberoptic bronchoscopy were carried in the operating room and ICU. Bronchodilators, antibiotics, steroids and diuretics were also used to treat pneumonia. The patient was treated successfully without any complication. (Korean J Anesthesiol 2011; 61: 251-256)

Key Words: Aspiration pneumonia, PEEP, Povidone iodine.

Severe respiratory disorders can occur when foreign bodies are aspirated into the bodies of those who are under general anesthesia or who have consciousness disorders. In particular, gastric contents are known to cause severe pulmonary complications when they are aspirated into lungs. Povidone iodine, an oral antiseptic, is widely used for oral disinfection in the preoperative stage. While reports of aspiration pneumonia caused by gastric contents are plentiful [1-5], aspiration pneumonia caused by povidone iodine is rarely reported $[6,7]$. We present a case of successfully treated pulmonary damage inflicted by the aspiration of povidone iodine without any complication.

\section{Case Report}

A 16-year old female patient (45 kg in weight and $157 \mathrm{~cm}$ in height) visited our hospital due to left maxillary fracture. The patient had no history of pulmonary disease, such as asthma, and showed no special features in the electrocardiography, biochemical examination of blood, or chest X-ray, all of which were conducted before her operation (Fig. 1). As a preoperative preparation, $0.05 \mathrm{mg} / \mathrm{kg}$ of midazolam was injected 1 hour before beginning the operation. Vital signs before anesthesia were blood pressure 110/66 $\mathrm{mmHg}$, heart rate 80 beats $/ \mathrm{min}$, and oxygen saturation $99 \%$. After arrival in the operating room,

Received: December 7, 2010. Revised: 1st, January 18, 2011; 2nd, February 8, 2011; 3rd, March 1, 2011. Accepted: March 2, 2011.

Corresponding author: Tae-Hun An, M.D., Department of Anesthesiology and Pain Medicine, School of Medicine, Chosun University, 588, Seoseok-dong, Dong-gu, Gwangju 501-717, Korea. Tel: 82-62-220-3223, Fax: 82-62-223-2333, E-mail: than@chosun.ac.kr

(c) This is an open-access article distributed under the terms of the Creative Commons Attribution Non-Commercial License (http:// creativecommons.org/licenses/by-nc/3.0/), which permits unrestricted non-commercial use, distribution, and reproduction in any medium, provided the original work is properly cited. 


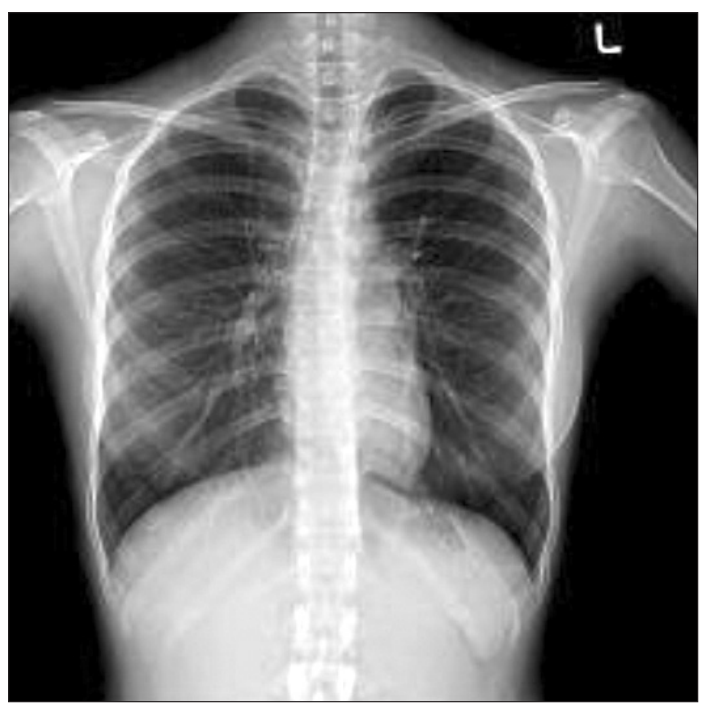

Fig. 1. Normal chest x-ray taken before induction.

the patient's condition was monitored by a non-invasive blood pressure, pulse oxymeter, and electrocardiograph. The patient lost consciousness following the induction of anesthesia with 2 $\mathrm{mg} / \mathrm{kg}$ propofol. An injection of $0.6 \mathrm{mg} / \mathrm{kg}$ rocuronium stopped spontaneous breathing, leading to positive pressure ventilation. Before a Mallinckrodt tube (Mallincrodt, St. Louis, MO, USA) with an internal diameter of $7.0 \mathrm{~mm}$ was inserted, no leakage in the tube cuff was found through ballooning of the cuff. A tracheal intubation was performed after confirmation that the patient's muscles were sufficiently relaxed. $6 \mathrm{ml}$ of air was then inserted and no leakage of air in the mouth was heard. Pressure inside the cuff was also monitored using a control inflator and maintained at $20 \mathrm{mmHg}$. Following tracheal intubation, normal breathing sound was confirmed through auscultation. A wire was fastened around the tube at the " $19 \mathrm{~cm}$ " mark to fix the tube to one of the teeth on the lower right side of the mouth. Tidal volume and respiration rate were maintained at $10 \mathrm{ml} /$ $\mathrm{kg}$ and 10 per minute, respectively, by an anesthetic machine (Cato, Dräger, Germany). Peak inspiratory pressure was 15 $\mathrm{cmH}_{2} \mathrm{O}$, and there was no air leakage in end-inspiration and no non-repletion of the bellow. Anesthesia was maintained by $2 \mathrm{~L} / \mathrm{min}$ of $\mathrm{O}_{2}, 2 \mathrm{~L} / \mathrm{min}$ of $\mathrm{N}_{2} \mathrm{O}$, and $2.5 \mathrm{vol} \%$ of sevoflurane. For oral irrigation, povidone iodine (Betadine ${ }^{\circledR}$, Koreapharma, Korea) was used. During irrigation, bubbles formed, so $2 \mathrm{ml}$ of additional air was inserted into the cuff. However, bubbles continued to form and the tube was removed after the povidone iodine inside the mouth was drawn through a suction catheter. Afterwards, tracheal intubation was retaken with a new Mallinckrodt tube the same size as the previous one. $6 \mathrm{ml}$ of air was inserted into the cuff to maintain the inside-cuff pressure at $20 \mathrm{mmHg}$. The new tube was also $19 \mathrm{~cm}$ into the throat and

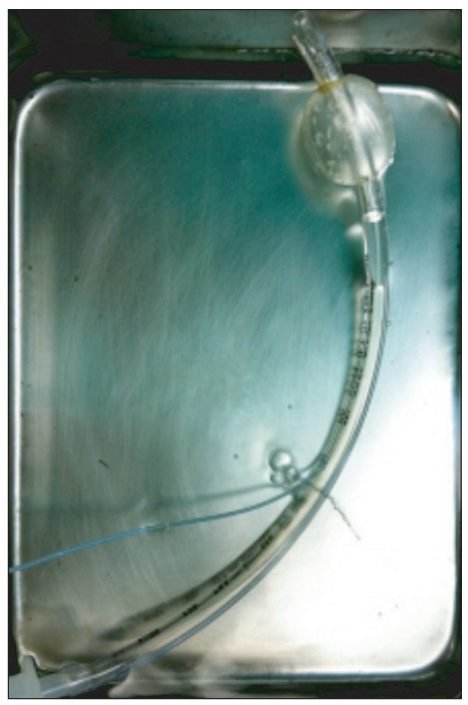

Fig. 2. Extubated endotracheal tube: the inflating tube between cuff and pilot of the tube is perforated by the wire.

fastened with a wire to one of the teeth on the lower right side of the mouth. Normal breathing sound from both lungs was heard and pulse oxygen saturation was $100 \%$. Moreover, lung compliance and chest movement were normal and thus oral irrigation was resumed. No more air leakage occurred and maximum inspiratory pressure was $17 \mathrm{cmH}_{2} \mathrm{O}$. It was strange that air leakage was found in the first intubation, while no leakage was found in the second trial. Air was inserted into the cuff of the first tube, which was removed, to identify the reason. Consequently, it was found that air came out through a minute hole between the cuff and pipe connecting the pilot (Fig. 2). It was speculated that the tube was damaged when the wire was fastened to the tube.

Thirty minutes after beginning of the operation, oxygen saturation declined from $99 \%$ to $96 \%$ and a rale was heard from the right lung through auscultation. The operation was immediately stopped and tracheal suction was commenced using a suction catheter. As a result, frothy discharge came out instead of povidone iodine.

A chest X-ray was conducted on suspicion of aspiration pneumonia. For continuous arterial blood gas analyses, an invasive arterial catheter was inserted into the left radial artery after collateral circulation was confirmed through the Modified Allen's test. Results were as follows: $\mathrm{FiO}_{2}$ 0.5, $\mathrm{pH}$ 7.34, $\mathrm{PaCO}_{2} 42.9$ $\mathrm{mmHg}, \mathrm{PaO}_{2} 69.4 \mathrm{mmHg}$, and $\mathrm{SaO}_{2} 93 \%$ (Table 1). Following the analysis, salbutamol (Ventolin ${ }^{\circledR}$, GSK, UK) was nebulized through the tracheal tube while conducting mechanical ventilation with $10 \mathrm{cmH}_{2} \mathrm{O}$ of positive end-expiratory pressure (PEEP). In addition, $90 \mathrm{mg}$ of methylprednisolone and $20 \mathrm{mg}$ of furosemide were injected. Meanwhile, the chest X-ray determined aspiration pneumonia in the right lung (Fig. 3). Thirty 
Table 1. Arterial Blood Gas Analysis in the Operating Room and Intensive Care Unit

\begin{tabular}{lccccccc}
\hline & $\begin{array}{c}30 \text { min after } \\
\text { operation }\end{array}$ & $\begin{array}{c}60 \text { min after } \\
\text { operation }\end{array}$ & $\begin{array}{c}90 \mathrm{~min} \\
\text { after operation }\end{array}$ & $\begin{array}{c}2 \mathrm{~h} \\
\text { after MV }\end{array}$ & $\begin{array}{c}18 \mathrm{~h} \\
\text { after MV }\end{array}$ & $\begin{array}{c}2 \mathrm{~h} \\
\text { after T-piece }\end{array}$ after extubation \\
\hline $\mathrm{FiO}_{2}$ & 0.5 & 1.0 & 1.0 & 0.4 & 0.3 & 0.3 & 0.28 \\
$\mathrm{pH}$ & 7.34 & 7.35 & 7.39 & 7.54 & 7.49 & 7.36 & 7.39 \\
$\mathrm{PaCO}_{2}(\mathrm{mmHg})$ & 42.9 & 39.6 & 36.9 & 20.5 & 21.9 & 40.5 & 35.7 \\
$\mathrm{PaO}_{2}(\mathrm{mmHg})$ & 69.4 & 253.3 & 131.8 & 173.9 & 111.8 & 176.5 & 182.1 \\
$\mathrm{BE}_{(\mathrm{mmol} / \mathrm{L})}$ & -3 & -3.7 & -2.3 & -2.7 & -4.4 & -2.9 & -2.7 \\
$\mathrm{SaO}_{2}(\%)$ & 93 & 99.6 & 98.6 & 99.4 & 98.5 & 99.2 & 99.3 \\
\hline
\end{tabular}

MV: mechanical ventilation.

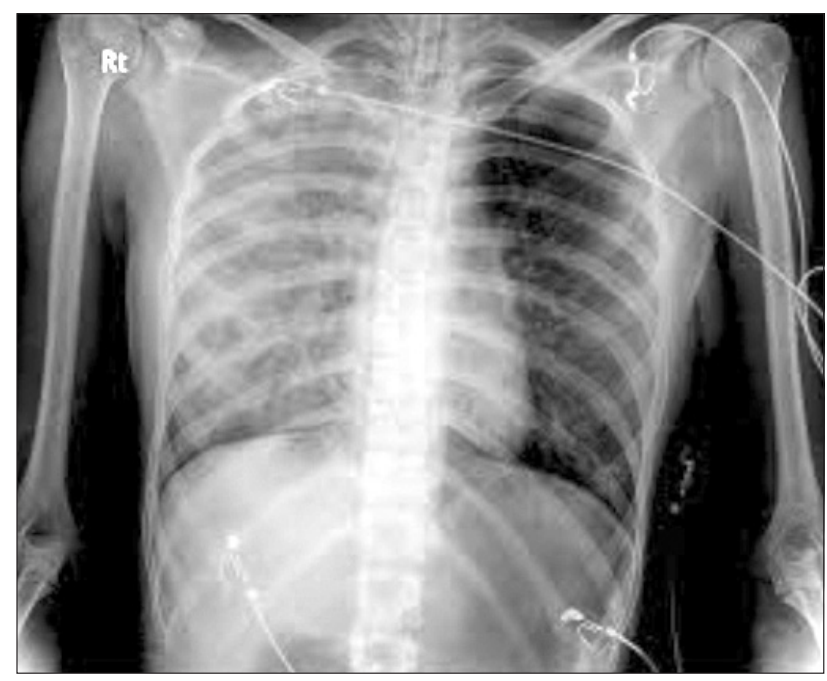

Fig. 3. Chest X-ray taken after reintubation: pneumonic infiltration and atelectasis shown on right lung field.

minutes after administration of drug treatment and mechanical ventilation, arterial blood gas analysis was conducted again. The analysis showed improvement in the patient's condition as follows: $\mathrm{pH}$ 7.35, $\mathrm{PaCO}_{2} 39.6 \mathrm{mmHg}, \mathrm{PaO}_{2} 253.3 \mathrm{mmHg}$, and $99 \% \mathrm{SaO}_{2}$. Accordingly, the operation was resumed and finished 30 minutes later. After the operation, $10 \mathrm{mg}$ pyridostigmine and $0.4 \mathrm{mg}$ glycopyrrolate were used to reverse muscle relaxation. As the patient's spontaneous respiration recovered, brownishtinged liquid was discharged while her lung compliance decreased. Afterwards, suction through the tube was administered resulting in substantial aspiration of povidone iodine. Additional suction of povidone iodine was performed after the trachea and bronchi were cleaned with sterile saline solution under the guidance of fiberoptic bronchoscopy. Subsequently, compliance of the reservoir bag improved and arterial blood gas analysis at this point showed $\mathrm{FiO}_{2}$ 1.0, pH 7.36, $\mathrm{PaCO}_{2} 36.9$ $\mathrm{mmHg}, \mathrm{PaO}_{2} 131.8 \mathrm{mmHg}$, and $\mathrm{SaO}_{2} 98.6 \%$. The patient was transferred to the intensive care unit with the tracheal tube still inside.

In the intensive care unit, further suction of povidone iodine was attempted using bronchoscopy, but no such liquid was

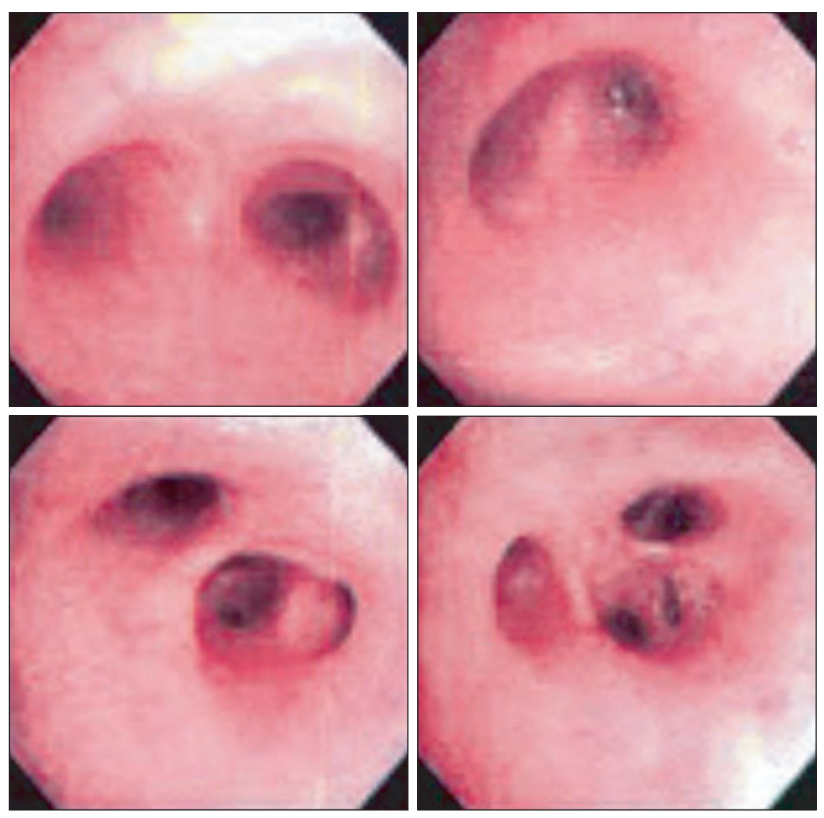

Fig. 4. Bronchoscopic pictures taken in the ICU: betadine solution was not shown.

found (Fig. 4). Tidal volume of the patient was as insufficient as 200-250 ml. Therefore, mechanical ventilation was performed at the pressure support mode with 0.4 of $\mathrm{FiO}_{2}$, while pressure support was $15 \mathrm{cmH}_{2} \mathrm{O}$ and PEEP was $10 \mathrm{cmH}_{2} \mathrm{O}$. At this moment, exhaled tidal volume was $350-400 \mathrm{ml}$ and respiration rate was $15-17$ per minute. The arterial blood gas analysis conducted 5 hours after the beginning of the mechanical ventilation found a $\mathrm{pH}$ of 7.54, $\mathrm{PaCO}_{2} 20.5 \mathrm{mmHg}, \mathrm{PaO}_{2} 173.9$ $\mathrm{mmHg}$, and $\mathrm{SaO}_{2} 99.4 \%$. Biochemical examination of blood was also conducted, and the results were as follows: leukocyte counts were $13.840\left(10^{3} / \mu \mathrm{l}\right)$, neutrophils had increased to $88.2 \%$, and her body temperature was $37.4^{\circ} \mathrm{C}$ leading to the diagnosis of fever. Accordingly, augmentin (Augmentin ${ }^{\circledR}$, Ilsung, Korea) along with cefepime (Maxipime ${ }^{\circledR}$, Boryung, Korea) were prescribed, while $20 \mathrm{mg}$ of methylprednisolone and furosemide each were administered 3 times and twice a day, respectively. At this point, pressure support and PEEP were readjusted to 8 $\mathrm{cmH}_{2} \mathrm{O}$ and $5 \mathrm{cmH}_{2} \mathrm{O}$, respectively. Arterial blood gas analysis 


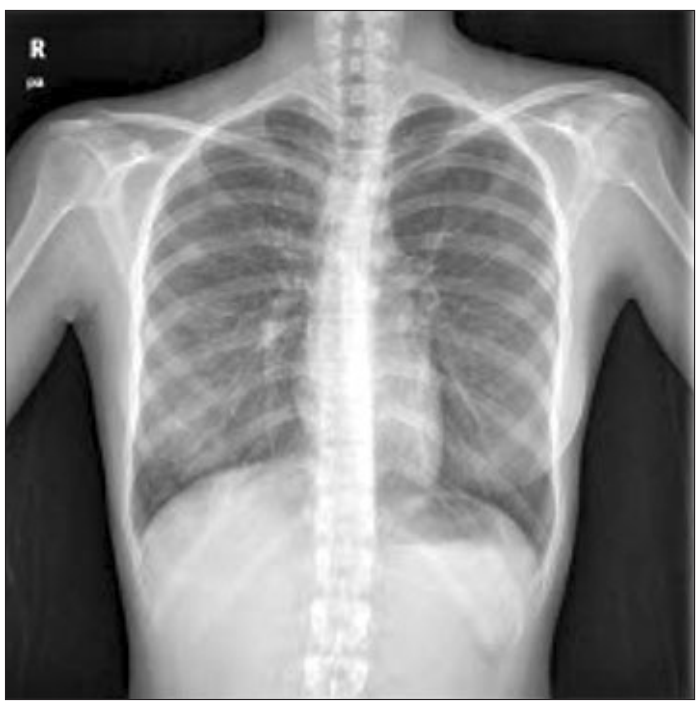

Fig. 5. Chest x-ray after extubation: right lung field shows nearly normalizing.

conducted 18 hours after beginning mechanical ventilation presented pH 7.49, $\mathrm{PaCO}_{2} 21.9 \mathrm{mmHg}, \mathrm{PaO}_{2} 111.8 \mathrm{mmHg}$, and $\mathrm{SaO}_{2}$ 98.5\%. Weaning was performed when 25 hours had passed since the beginning of mechanical ventilation using a T-piece, and $3 \mathrm{~L} / \mathrm{min}$ of oxygen was provided to the patient. Her blood pressure and heart rate were normal while oxygen saturation remained $98 \%$ or higher. The patient's consciousness was so clear that she could follow a pen with her eyes. Removal of the tube was conducted 2 hours after weaning, as arterial blood gas analysis at this time indicated $\mathrm{pH} 7.36, \mathrm{PaCO}_{2} 40.5 \mathrm{mmHg}$, $\mathrm{PaO}_{2} 176.5 \mathrm{mmHg}$, and $\mathrm{SaO}_{2} 99.2 \%$. After removal of the tube, $2 \mathrm{~L} / \mathrm{min}$ of oxygen was provided through a nasal cannula, and arterial blood gas analysis conducted 5 hours after this showed $\mathrm{pH}$ 7.39, $\mathrm{PaCO}_{2} 35.7 \mathrm{mmHg}, \mathrm{PaO}_{2} 182.1 \mathrm{mmHg}$, and $\mathrm{SaO}_{2} 99.3 \%$. Oxygen saturation remained $98 \%$ or higher, and the amount of oral discharge gradually decreased. The patient's chest X-ray also indicated improvement in her condition (Fig. 5). Fifty hours after the operation, the 16-year old girl was transferred to a general ward without any complication.

\section{Discussion}

Aspiration pneumonia, which occurs during an operation, is a pulmonary complication usually caused by aspiration of gastric contents. It is also known as Mendelson's syndrome [1]. The severity of this complication is determined by the amount and acidity of aspirated contents. The occurrence rate is one in 3,000 cases, and it accounts for $10-30 \%$ of anesthesia-related deaths $[2,3]$.

Pulmonary aspiration can occur in the following cases where: fast time is 8 hours or less; patients are pregnant; or patients suffer from injuries, bowel obstruction, gastrointestinal disorders, esophageal disorders, or obesity [8]. Symptoms of the complication include wheezing, cough, dyspnea, cyanosis, pulmonary edema, hypotension, hypoxia, and even acute respiratory failure [9]. Aspiration pneumonia is known to occur when the $\mathrm{pH}$ of gastric contents is 2.5 or less and the amount of contents is $20 \mathrm{ml}(0.3 \mathrm{ml} / \mathrm{kg})$ or more. Even if the $\mathrm{pH}$ is over 2.5, the complication can occur depending on ingredients of the contents [2]. Pulmonary aspiration during general anesthesia can take place anytime in the perioperative period. It mainly occurs during removal of a tracheal tube (35.9\%) or manipulation of a laryngoscope. It is reported that the aspiration can occur anytime during operation and within two hours after anesthesia has ceased, while $10 \%$ of cases occur during anesthesia [3].

In this paper, we report a case where aspiration pneumonia was inflicted by povidone iodine, which is used as an oral antiseptic. Such a case is fairly rare [6,7]. Povidone iodine is also used as a preoperative preparation applied to skin, mucous membranes, and scars. $10 \%$ povidone iodine ( $\mathrm{pH} 5.0)$ is commonly used since its antibacterial effect is strong due to the concentration of free $\mathrm{I}_{2}$ [7].

Air leakage after tracheal intubation can take place for various reasons: insufficient air, low pressure inside the cuff, and rupture of the cuff are among them. Leakage can also happen when the cuff, hanging around vocal cords, excessively expands to the oropharynx. Types of air leakage in the cuff can differ according to the type of tube. Liquid leakage has been reported in Portex soft seal tubes (Portex, Kent, UK) and Mallinckrodt tubes (Mallinckrodt, St. Louis, MO, USA), both of which are cuff tubes of large capacity and low pressure. This is because these two types of tubes have paths for liquid. In contrast, Bivona aircuffs (Bivona, Gary, IN, USA) and Bivona Fome-cuffs (Bivona, Gary, IN, USA), which are small capacity and low pressure cuff tubes, are reported to have relatively low risk of liquid leakage since they have no path for liquid $[4,10]$. In our case, air leakage might have occurred because Mallinckrodt tubes were used. However, we cannot attribute the aspiration pneumonia to leakage due to the Mallinckrodt tubes because the complication developed in such short time.

It is recommended that cuff pressure be maintained at 25-35 $\mathrm{cmH}_{2} \mathrm{O}$ while air pressure is continuously monitored. Methods to verify appropriate cuff pressure include pilot balloon palpation technique, minimum occlusive volume technique, minimum leak technique, and predetermined volume method. In our case, we measured the pressure with a control inflator. We also found no air leakage in the mouth and lungs through auscultation, reaching a conclusion that there was no air leakage around the cuff. After removal of the first tracheal tube, however, a tiny hole was discovered in the inflating tube 
connecting the pilot and tube cuff. It was speculated that the hole was made by the wire used to fasten the cuff to the patient's tooth. Accordingly, we surmise that this tube damage led to the air leakage, which in turn caused the pulmonary aspiration.

For patients with pulmonary aspiration, suction of aspirated contents is the most important step in treatment. One of the options is to switch the patient to a lateral position and to administer chest percussion. However, this method is not as effective as suction. Therefore, endotracheal suction with the guidance of fiberoptic bronchoscopy is required to draw the contents situated in distal areas of the trachea [5]. For the treatment of acute respiratory failure caused by aspiration pneumonia, mechanical ventilation using PEEP should be performed. If patients show symptoms of clinical infection, antibiotics should be administered. Although preventative antibiotic administration is known to be undesirable [11], we did so since our patient showed an inflammatory symptom. Despite the current controversy on the use of steroids, $1 \mathrm{mg} /$ $\mathrm{kg}$ of methylprednisolone per day is recommended as an initial dose. Its beneficial effects usually appear 3 days after initial administration. In addition, it has been reported that proper use of diuretics and restriction of fluid provision help patients recover pulmonary function $[12,13]$. Mechanical ventilation using PEEP is also known to be beneficial for the prognoses of those who have suffered from acute respiratory distress syndrome (ARDS) caused by aspiration pneumonia. The reason is that such mechanical ventilation minimizes the damage of alveoli during the respiratory period by recruiting collapsed alveoli early and opening them when the patients breathe [14].

When oxygen saturation decreased during the operation in our case, we immediately conducted a chest X-ray and arterial blood gas analysis, which found hypoxemia $\left(\mathrm{FiO}_{2} 0.5, \mathrm{PaO}_{2}\right.$ $\left.69.4 \mathrm{mmHg}, \mathrm{PaO}_{2} / \mathrm{FiO}_{2}<300\right)$. On suspicion of ARDS caused by aspiration of povidone iodine, mechanical ventilation using $10 \mathrm{cmH}_{2} \mathrm{O}$ of PEEP was conducted. We then attempted suction of povidone iodine and clean-up of the trachea and bronchus using fiberoptic bronchoscopy. The patient was transferred to the intensive care unit after the operation and the mechanical ventilation using PEEP continued. Antibiotics were administered due to symptoms of inflammation and acute pulmonary damage caused by pneumonia. To prevent pulmonary edema, steroids and diuretics were used.

Numazawa et al. [7] reported cases where pulmonary aspiration of povidone iodine occurred in patients with a history of bronchial asthma. The povidone iodine permeated into hypersensitive areas in the airway and inflicted transient bronchospasm and atelectasis. Our patient was female without any history of pulmonary disease. However, her chest X-ray confirmed that the damage to her right lung was worsening rapidly due to aspiration of povidone iodine, and arterial blood gas analysis found severe hypoxia $\left(\mathrm{FiO}_{2} 0.5, \mathrm{PaO}_{2} 69.4 \mathrm{mmHg}\right.$, $\left.\mathrm{PaO}_{2} / \mathrm{FiO}_{2}<300\right)$. As seen in our case, pulmonary aspiration caused by povidone iodine can destroy lungs quickly (within 1 hour of aspiration); thus, swift diagnosis and treatment are most critical. Our patient recovered without any complication, although she had severe hypoxia. We suggest such a result was possible since we diluted $10 \%$ povidone iodine to $1 \%$ before using it. In addition, we withdrew the povidone iodine with the guidance of fiberoptic bronchoscopy in a relatively short time after pulmonary aspiration occurred. Several measures were also taken including mechanical ventilation using PEEP and various drug treatments.

Common measures to prevent aspiration pneumonia are head elevation during induction of general anesthesia, Sellick's maneuver, and the use of a tube with low-capacity and lowpressure cuff. To prevent aspiration pneumonia that can occur during oral disinfection with povidone iodine, depth of the tracheal tube and pressure inside the cuff are important factors. It is recommended to pack a tube with cotton to prevent leakage, and diluting povidone iodine is also important.

Our patient developed severe hypoxia even though she had no record of pulmonary disease. Prevention is most important for patients with a high-risk of pulmonary aspiration. Operators should be well aware of risk factors for pulmonary aspiration and should take extra caution to avoid tube damage when they need to fasten tubes with wires. If pulmonary aspiration occurs, appropriate treatments should be administered as quickly as possible. It is also important to check through bronchoscopy when aspiration is suspected. When oral disinfection with povidone iodine is administered, as in our case, operators should always consider the possibility of pulmonary aspiration and always be cautious to prevent aspiration pneumonia, which can occur during anesthesia induction or in the midst of anesthesia.

\section{References}

1. Mendelson CL. The aspiration of stomach contents into the lungs during obstetric anesthesia. Am J Obstet Gynecol 1946; 52: 191-205.

2. Olsson GL, Hallen B, Hambraeus-Jonzon K. Aspiration during anaesthesia: a computer-aided study of 185,358 anaesthetics. Acta Anaesthesiol Scand 1986; 30: 84-92.

3. Warner MA, Warner ME, Weber JG. Clinical significance of pulmonary aspiration during the perioperative period. Anesthesiology 1993; 78: 56-62.

4. Choi WJ, Kyoung MK, Kim YC, Moon SH, Kim YH, Kim HS. Aspiration pneumonia at recovery room in the patient emergency pelviscopic salpingectomy, without the perceptive sign of gastric regurgitation during perioperative periods. Korean J Anesthesiol 2007; 52: 612-6.

5. Choi SH, Lee SJ, Yoon KB, Han S, Kim JH. Fiberoptic bronchoscopic treatment of pulmonary aspiration occurring in a child during 
induction of anesthesia -A case report. Korean J Anesthesiol 2005; 49: 744-7.

6. Howe DJ. Aspiration pneumonia from povidone-iodine (Betadine): report of case. J Oral Surg 1981; 39: 224-5.

7. Numazawa R, Morimoto Y, Yokota S, Yamamura T, Kemmotsu O. Pneumonia due to aspiration of povidone-iodine during anesthesia--a case report. Masui 1992; 41: 846-9.

8. Gal TJ. Airway management. In: Miller's Anesthesia. 6th ed. Edited by Miller RD: New York, Elsevier Churchill Livingstone. 2005, pp 1617-52.

9. Gibbs CP, Modell JH. Pulmonary aspiration of gastric contents: pathophysiology, prevention, and management. In: Miller's Anesthesia. 4th ed. Edited by Miller RD: New York, Churchill Livingstone. 1994, pp 1437-64.
10. Young PJ, Pakeerathan S, Blunt MC, Subramanya S. A low-volume, low-pressure tracheal tube cuff reduces pulmonary aspiration. Crit Care Med 2006; 34: 632-9.

11. Barash PG, Cullen BF, Stoelting RK. Handbook of clinical anesthesia. 5th ed. Philadelphia, Lippincott Williams \& Wilkins. 2005, pp 1393-5.

12. Meduri GU, Marik PE, Annane D. Prolonged glucocorticoid treatment in acute respiratory distress syndrome: Evidence supporting effectiveness and safety. Crit Care Med 2009; 37: 1800-3.

13. Calfee CS, Matthay MA. Nonventilatory treatments for acute lung injury and ARDS. Chest 2007; 131: 913-20.

14. Paulson TE, Spear RM, Silva PD, Peterson BM. High-frequency pressure-control ventilation with high positive end-expiratory pressure in children with acute respiratory distress syndrome. J Pediatr 1996; 129: 566-73. 